\title{
Measurement and analysis of parameters of the precise grinding system
}

\author{
Krzysztof Tyszczuk ${ }^{1 *}$, Kazimierz Peszyński ${ }^{2}$, Adam Mroziński ${ }^{2}$, and Grzegorz Śmigielski ${ }^{1}$ \\ ${ }^{1}$ Kazimierz Wielki University in Bydgoszcz, Poland \\ ${ }^{2}$ University of Science and Technology in Bydgoszcz, Poland
}

\begin{abstract}
The technological process of materials grinding, especially biological material with high oil content, is quite complex. There are several parameters that impact the performance and quality of the process (e.g. temperature, rotational speed). One of them is the air velocity at pneumatic conveying of grinding particles. The phenomena of pneumatic transport of seeds and its impact on product's quality and grinding capacity is not methodologically recognized so far. The paper presents the construction details of measurement and control system and results of the research obtained during the laboratory tests. The results of the tests and their analysis will be used for design of a commercial precise grinder, which allowed to reach the optimum product's capacity and quality, constituting the basis for biological diet supplements.
\end{abstract}

Keywords: size reduction, oilseeds, pneumatic conveying, biological food supplements, measurement system

\section{Precision grinding system}

The preparation of plant-based supplements, especially seeds with high oil content, requires a special design of the shredder and continuous control of the process parameters [1-4]. In order to obtain the required features of the material (without extracting oil), during precision grinding, the following parameters have to be controlled: rotational speed, linear speed of knife, material feeding speed and vacuum in the installation. Assuming a constant aspirator rate (Fig. 1 - D), too high feed flow rate (Fig. 1 - A) causes of the production of material with an inadequate particle size distribution. Based on various simulations $[1,3,4]$, a material flow model was developed.

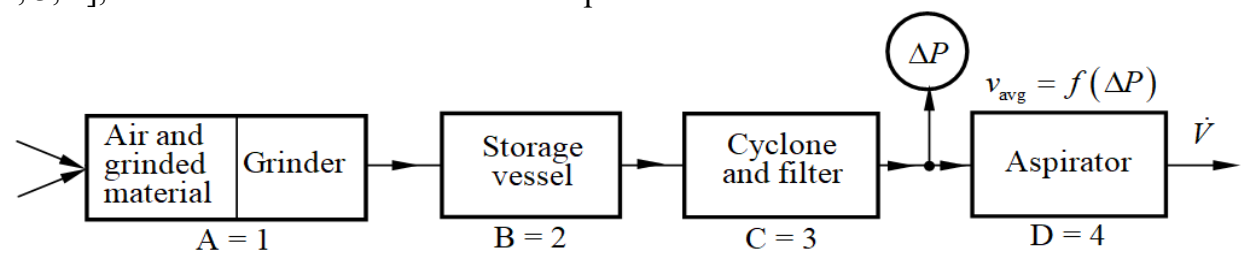

Fig. 1. Division of the technological line into measuring sections [5]

\footnotetext{
*Corresponding author: krzytysz@ukw.edu.pl

Reviewers: Tomasz Domański, Radim Halama
} 
The complete precise grinding testing line is shown in Fig. 2. A computer application making it possible to measurement of parameters of the grinding system, control the performing devices and to visualize the process variables, has been developed in the LabVIEW environment [6].

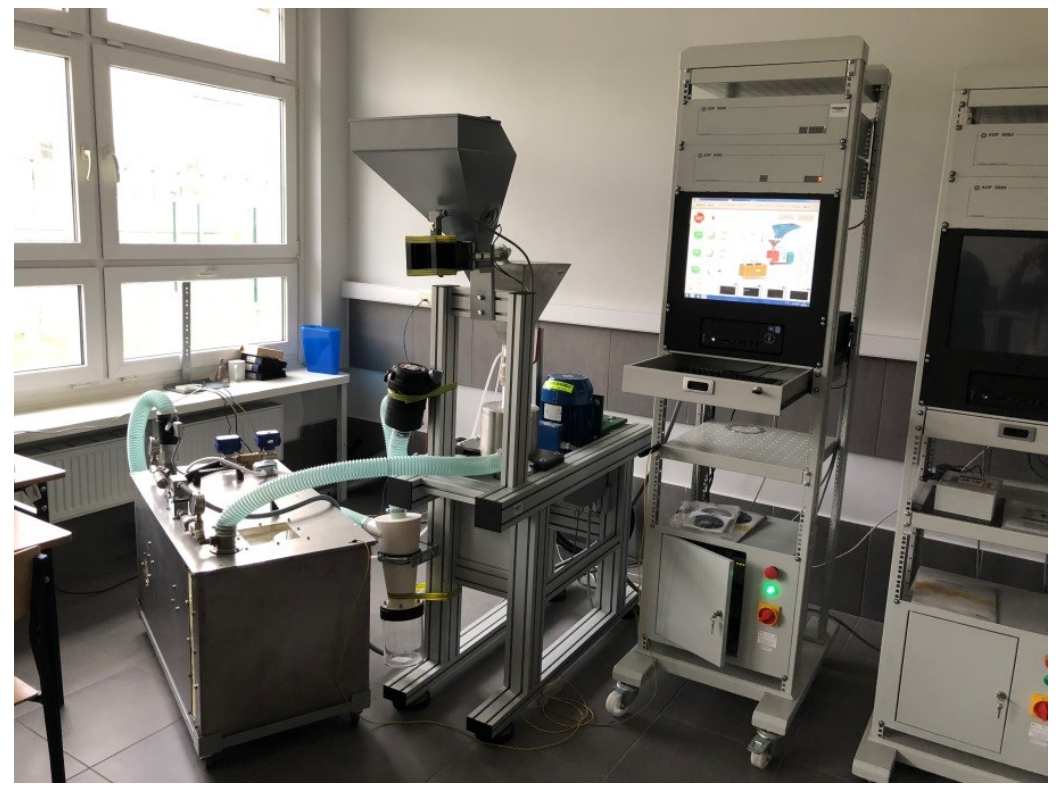

Fig. 2. View of the real test stand of precise seeds' grinding with pneumatic transport

Thanks to the identification of changes in the pneumatic installation, it became possible to optimally fill the grinder with material, obtaining the maximum process efficiency [7-10] and the desired form of seed fragmentation. In the preparation of dietary supplements, based on oilseeds, grinding particles should be within $0.6-0.8 \mathrm{~mm}$, which guarantees very good mixing with liquids and high digestibility and assimilation by the body (Fig. 3).
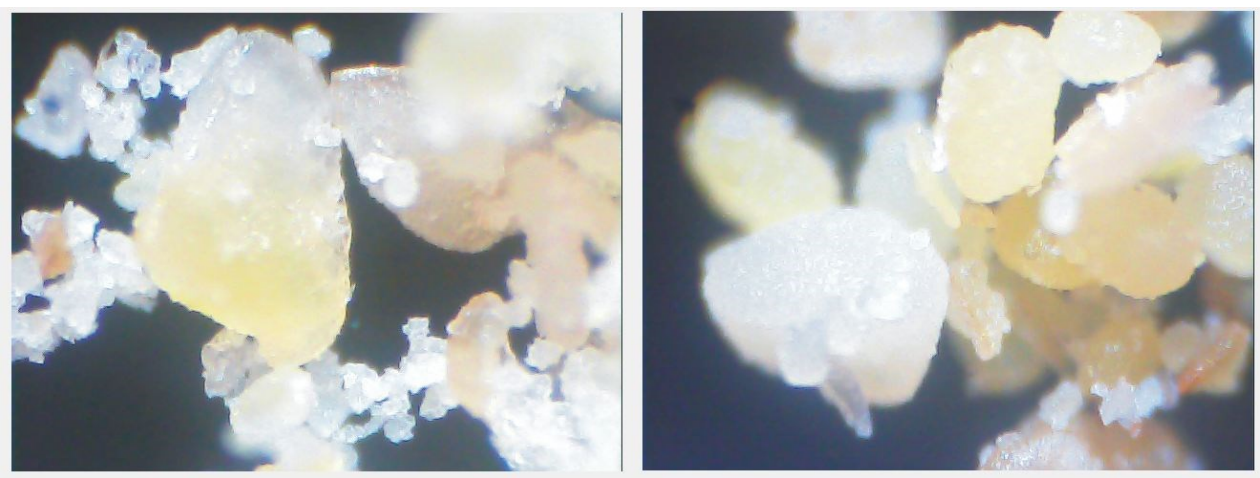

Fig. 3. View of the seeds after grinding: golden flax and mustard 


\section{Impact of the grinder rotational speed on the pneumatic grinder transfer function}

In the paper [5] a mathematical model of the pneumatic grinder system designated for the air flow through this system without grinding material was presented. This model was determined for one rotational speed of the grinder $\left(\omega_{\mathrm{gr}}=25 \mathrm{~s}^{-1} \approx 157 \mathrm{rad} \cdot \mathrm{s}^{-1}\right)$. This raises the question: what is the impact of the grinder rotational speed on the air flow through the system. The answer to this question is illustrated in Fig. 4.

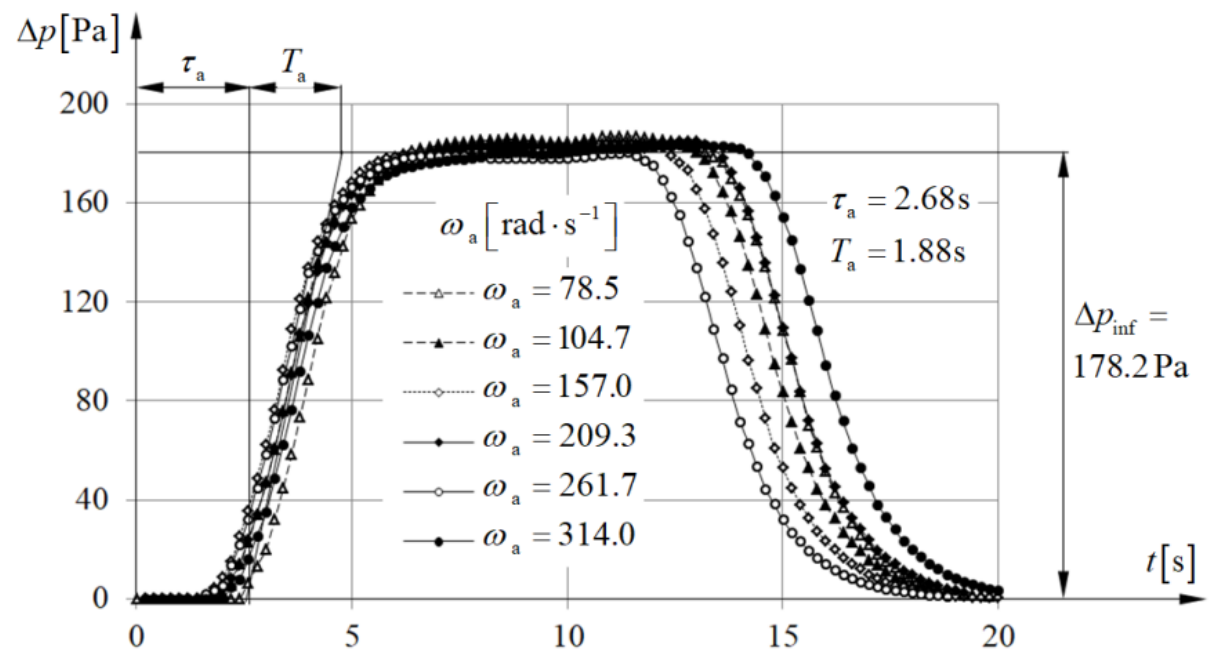

Fig. 4. Influence of the grinder rotational speed on the process line properties

From Fig 4, it can be clearly stated that this effect is negligible. Since the quality and efficiency of the grinding depends on the rotational speed of the grinder, it means that this speed can be selected freely without affecting the dynamic properties of the line, which greatly simplifies the possible control process. Finally, on the basis of Fig. 4, we can write transfer function of the grinding technological line for flow of pure air, in form of $1^{\text {st }}$ order element with delay

$$
G(s)=\frac{178.2 e^{-2.68 s}}{1.88 s+1}
$$

Note, that this transfer function is different from those transfer function presented in [5]. This is caused by the change of the filter in the process line. The numerical parameters were determined in the same way as in [5] as the average value of all six measurements.

\section{Extended mathematical model of pneumatic system}

An important problem is to determine the impact of the grinded material added to the air (see Fig. 1) on the found mathematical model. First, it is necessary to determine after what time the charging cone can be opened from the start of the production line. It was assumed that when opening the charging cone, there should be a fixed air flow. In industrial practice, it is assumed that for a first order static element, the steady state is after time $t=3 T$, where $T$ is the time constant of this element $[1,5]$. In the analysed process $T=T_{\mathrm{a}}$, after time $3 T_{\mathrm{a}}$ the vacuum value in the system will be equal to 


$$
\Delta p=\Delta p_{\text {inf }}\left(1-e^{-\frac{3 T_{\mathrm{a}}}{T_{\mathrm{a}}}}\right)=178.2\left(1-e^{-3}\right)=169.3 \mathrm{~Pa} \approx 0.95 \Delta p_{\text {inf }}
$$

therefore, the opening time $\tau_{\mathrm{v}}$ of the charging valve is at least

$$
\tau_{\mathrm{v}} \geq \tau_{\mathrm{a}}+3 T_{\mathrm{a}}=2.68+3 \cdot 1.88=8.32 \mathrm{~s}
$$

for the presented analysis, it was adopted $\tau_{v}=8.4 \mathrm{~s}$.

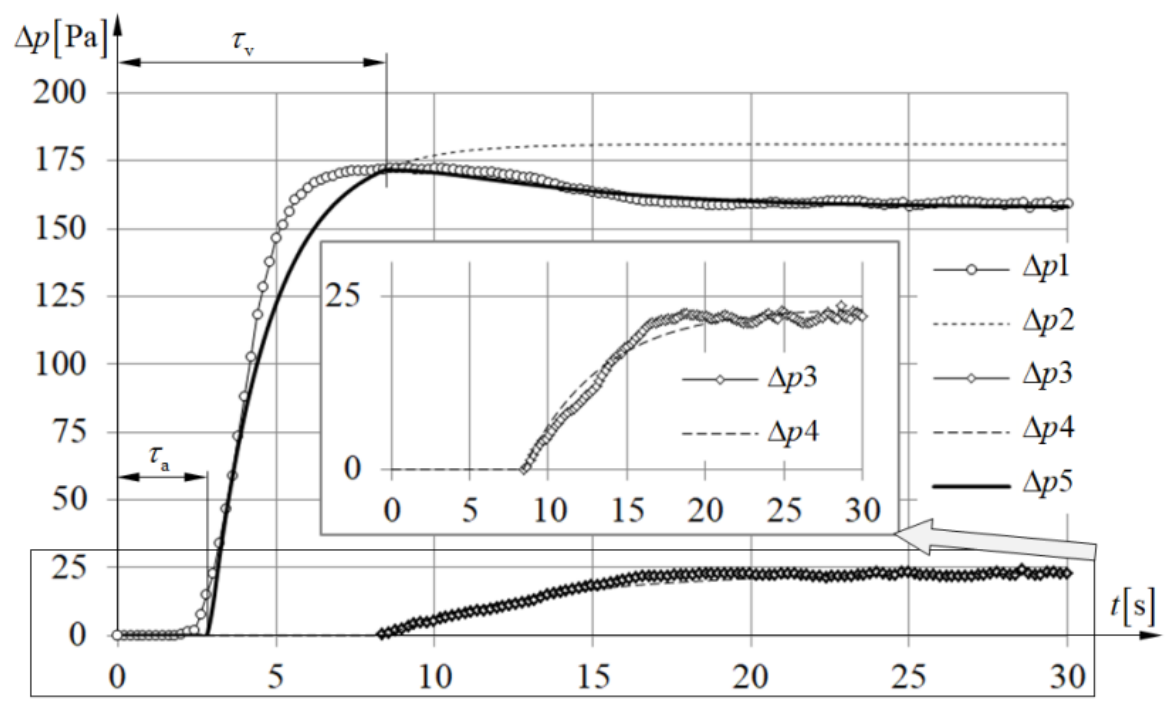

Fig. 5. Steps to create a mathematical model

The mathematical model, the image of which is shown in Fig. 5, was obtained in the following steps:

\section{Step 1 - curve $\Delta p 1$}

This curve is the result of the measurement on the test bench. After starting the aspirator time $\tau_{\mathrm{v}}=8.4 \mathrm{~s}$ was waiting and the valve of conical feed hopper was opened. Flax seeds in the amount $m^{\prime}=0.041 \mathrm{~kg} \cdot \mathrm{s}^{-1}$ were added to the flowing air.

Step 2 - curve $\Delta p 2$

It is a curve based on a mathematical model in the form of transfer function (1). In time, the equation of this curve has the form

$$
\Delta p 2=\left\{\begin{array}{cc}
0 \leq t<2.88 & 0 \\
t \geq 2.88 & 181.1\left(1-e^{-\frac{t-2.88}{1.88}}\right)
\end{array}\right.
$$

Note that $\Delta p_{\text {Inf }}=181.1 \mathrm{~Pa}$ different from that shown in (1) $\left(\Delta p_{\text {Inf }}=178.2 \mathrm{~Pa}\right)$.

Step 3 - curve $\Delta p 3$

This curve is the result of subtraction $\Delta p 1-\Delta p 2$ for $t \geq 8.4 \mathrm{~s}$

Step 4 - curve $\Delta p 4$

Curve $\Delta p 4$ is a mathematical model of the experimental curve $\Delta p 3$ in form 


$$
\Delta p 4=\frac{k_{\mathrm{s}} e^{-\tau_{\mathrm{v}}}}{T_{\mathrm{s}} s+1}=\frac{23.34 e^{-8.4}}{5.03 s+1}
$$

where: parameters $\tau_{s}$ and $T_{\mathrm{s}}$ found by the least squares method, by adjusting the curve in the form $k_{\mathrm{s}}\left(1-\exp \left(-\left(t-\tau_{\mathrm{v}}\right) / T_{\mathrm{s}}\right)\right)$ to results obtained by experimental test.

Step 5 - curve $\Delta p 5$

This curve (mathematical model of the pneumatic system in the grinder) is the result of subtraction $\Delta p 2-\Delta p 4$. In time, the equation of this curve has the form

$$
\Delta p 5= \begin{cases}0 \leq t<2.88 & 0 \\ 2.88 \leq t<8.4 & 181.1\left(1-e^{-\frac{t-2.88}{1.88}}\right) \\ t \geq 8.4 & 181.1\left(1-e^{-\frac{t-2.88}{1.88}}\right)-23.34\left(1-e^{-\frac{t-8.4}{5.03}}\right)\end{cases}
$$

Parameters of this model $k_{\mathrm{s}}=23.24 \mathrm{~Pa}$ and $T_{\mathrm{s}}=5.03 \mathrm{~s}$, for the current state of knowledge, should be determined experimentally for individual types of grains.

\section{Conclusions}

The influence of rotational speed of the shredder on the properties of the pneumatic system is negligible. The input element of the grinding line in the form of a conical feed hopper should be replaced with another element, e.g. a screw conveyor with adjustable speed. This change will allow you to control the output of the hopper, which has a significant impact on the quality and efficiency of grinding.

\section{References}

1. K. Tyszczuk, K. Peszyński, A. Mroziński, G. Śmigielski, Analysis and modeling of variables of the precise shredder's pneumatic material transport's system. MMS 2017, MATEC Web Conf., 157, 01020, (2018)

2. A. Sapietová, V. Dekýš, M. Sapieta, P. Pecháč, Application of computational and design approaches to improve carrier stability. Procedia Eng. 96, 410-418 (2014)

3. L. Jakubovičová, M. Sága, M. Vaško, Numerical study of influence of mutual slewig of roller bearing rings on the principal stresses at contact area. Scientific journal of Silesian University of Technology - Series Transport 84, 83-91 (2014)

4. P. Kopas, M. Sága, V. Baniari, M. Vaško, M. Handrik, A plastic strain and stress analysis of bending and torsion fatigue specimens in the low-cycle fatigue region using the finite element methods. Procedia Engineering 177, 526-531 (2017)

5. K. Tyszczuk, K. Peszyński, A. Mroziński, G. Śmigielski, Pneumatic supporting of the precise grinding of fine oil seeds' process. $24^{\text {th }}$ International Conference Engineering Mechanics Svratka, Czech Republic, (2018) 
6. G. Śmigielski, W. Toczek, R. Dygdała, K. Stefański, Metrological analysis of precision of the system of delivering a water capsule for explosive production of water aerosol. Metrology and Measurement Systems 23 (1), 47-58 (2016)

7. M. Macko, Economic-energetic analysis of multi-edge comminution of polymer recyclates. Przemysł Chemiczny, 92, 8, 1499-1500 (2013)

8. J. Flizikowski, M. Macko, J. Czerniak, A. Mroziński, Implementation of genetic algorithms into development of mechatronic multi-edge's grinder design. ASME 2011 Int. Mech. Eng. Congress and Exposition, IMECE, (2011)

9. P. Kopas, M. Blatnický, M. Sága, M. Vaško, Identification of mechanical properties of weld joints of AlMgSi07.F25 aluminium alloy. Metalurgija 56 (1-2), 99-102 (2017)

10. M. Macko, J. Flizikowski, The method of the selection of comminution design for nonbrittle materials. Conference Proceedings AIChE, Annual Meeting in Salt Lake City session: Comminution - Experiments, Theory \& Modeling, (2010) 